\title{
The use of UAV for slums land regularization: potentialities, hindrances and challenges
}

\section{SIGRADI2018 TECHNOPOLITICAS \\ xxii congresso da sociedade iberoamericana de gráfica digital 22th conference of the iberoamerican society of digital graphics 07|08|09|novembro|2018 iau usp | são carlos | sp br}

\author{
Marcel Fantin \\ Instituto de Arquitetura e Urbanismo - USP | Brazil | mfantin@sc.usp.br \\ Julio Cesar Pedrassoli \\ Universidade Federal da Bahia | Brazil | pedrassoli.julio@gmail.com \\ Guilherme Nelli Zaratine \\ Instituto de Arquitetura e Urbanismo - USP | Brazil | guilherme.zaratine@hotmail.com \\ Ivan Langone Francioni Coelho \\ Escola de Engenharia de São Carlos - USP | Brazil | ivan.coelho@usp.br
}

\begin{abstract}
The use of Unmanned Aerial Vehicle (UAV) can contribute significantly to land regularization activities of slums. This article seeks to demonstrate the potential use of UAV in slums land regularization, as well the hindrances and the challenges considering the normative aspects and the scientific and technological research associated to this type of aerial photogrammetric survey in Brazil. It is concluded that the standardization and scientific researches developed to date are far removed from the discussions about the right to housing, seek, in their vast majority, to meet demands associated with the interests of large capital, especially agribusiness.
\end{abstract}

Keywords: Photogrammetry; Unmanned Aerial Vehicle; Land regularization.

\section{INTRODUÇÃO}

O processo brasileiro de urbanização - industrialização, associado a baixos salários e ao elevado valor da terra urbanizada, foi determinante para que grande parte da classe trabalhadora construísse as suas moradias em favelas localizadas essencialmente em áreas de risco e/ou em regiões periféricas e subequipadas das cidades.

No Brasil, em 2010, existiam 6.329 favelas que somavam 11,4 milhões de pessoas residentes. Isso representa cerca de $6 \%$ da população total do país e um acréscimo significativo em comparação aos $3,1 \%$ de 1991. Entre 1991 e 2010, a população brasileira teve um aumento de cerca de $20 \%$, enquanto os residentes nos aglomerados subnormais (ou favelas) aumentou na ordem de $61 \%$ (IBGE, 1991; IBGE, 2010).

Esse fenômeno apresenta maior representatividade nas regiões metropolitanas. Na Região Metropolitana de São Paulo (RMSP), por exemplo, $18,9 \%$ da população residem em favelas. Em outras regiões metropolitanas do país, a porcentagem da população residente em favelas é ainda maior, sendo 53,9\% em Belém, 26,1\% em Salvador, 24,5\% em São Luís e 23,2\% em Recife (IBGE, 2010).

Essa lógica perversa impõe um contexto de negação de direitos constitucionais como moradia digna e acesso aos serviços públicos essenciais, assim como apresenta o desafio histórico de se empreender as ações necessárias à regularização fundiária e urbanística das favelas.
Como um dos maiores desafios a serem enfrentados pelas práticas de planejamento urbano na atualidade, a regularização fundiária e urbanística procura prover a segurança da posse do imóvel e o acesso à terra urbanizada a partir de intervenções que visam a melhoria das condições urbanísticas, habitacionais, sociais e ambientais. Assim, o paradigma dominante atual a respeito de projetos de urbanização de favelas aborda formas de melhoria das condições de vida de forma ampla dentro de uma comunidade, partindo da melhoria da infraestrutura física ao mesmo tempo em que advoga a participação de forma efetiva da população envolvida.

O desenho destas melhorias habitacionais e urbanísticas demandam informações geoespaciais que geralmente estão relacionadas aos dados sobre a planialtimetria do terreno, incluindo a delimitação das edificações existentes, vias, rede de drenagem, linhas de energia elétrica, sistemas de abastecimento de água, classificação de tipos de uso e ocupação do solo, limites administrativos, bem como informações sobre áreas de risco geotécnico e suscetíveis à inundação. Contudo, faltam informações geoespaciais adequadas e atualizadas para as favelas, uma vez que as mesmas são negligenciadas pelas coletas de dados oficiais. As fontes tradicionais de sensoriamento remoto, que poderiam auxiliar nessa tarefa, não são suficientes para abordar a complexidade das favelas, incluindo a identificação de unidades residenciais individuais, mapeamento detalhado de infraestruturas internas ou detalhamento das condições ambientais locais (Gevaert et al., 2018). 
A adoção de aerolevantamento embarcado em VANTs (Veículos Aéreos Não Tripulados), mais popularmente conhecidos como drones e definidos na legislação brasileira como RPA (Remotely-Piloted Aircraft), pode contribuir de forma significativa para atividades de regularização fundiária e urbanística de favelas. Dentre as vantagens em se utilizar essa ferramenta, cumpre mencionar a relação custo/benefício, rapidez de execução, precisão e nível de detalhamento das informações obtidas a partir de ortomosaicos georreferenciados e modelagem 3D frente às imagens de satélites e/ou aerofotogrametria embarcada em aeronaves tripuladas.

Entretanto, a utilização desta tecnologia demanda uma normatização compatível com as necessidades de levantamento em favelas e o desenvolvimento de pesquisas científicas e tecnológicas que permitam executar o mapeamento a contento.

Esse artigo, dividido em três etapas, objetiva apresentar as potencialidades, obstáculos e desafios da utilização desta tecnologia na regularização fundiária e urbanística de favelas. Para tanto, procura-se trazer exemplos que permitam compreender e identificar os diferentes caminhos que vêm sendo utilizados para a adoção dessa tecnologia em favelas, além de dois quadros, incluindo aspectos éticos e normativos para esse tipo de aplicação e um panorama quantitativo das pesquisas científicas sobre sensoriamento remoto com VANTs.

\section{METODOLOGIA}

A primeira etapa do presente artigo consiste em expor situações onde foram utilizados VANTs no mapeamento de favelas, incluindo mapeamentos participativos, projetos de urbanização e lutas e resistências. A ideia é fornecer uma visão panorâmica e, ao mesmo tempo, apresentar os requisitos técnicos com foco nas potencialidades e desafios para o uso desta ferramenta.

A segunda etapa envolve o levantamento de aspectos normativos e éticos sobre mapeamentos com VANTs em favelas, onde são abordadas as normas do Departamento de Controle do Espaço Aéreo (DCEA) e da Agência Nacional de Aviação Civil (ANAC) para o uso dessa ferramenta, assim como pressupostos éticos associados.

Uma abordagem prioritariamente quantitativa predomina na terceira etapa do trabalho. A análise parte da verificação da hipótese de que a recente emergência das pesquisas relacionadas à aerofotogrametria com VANTs no Brasil guarda relação com pesquisas conservacionistas relacionadas ao meio ambiente e tendências de mercado como agronegócio, sendo a temática da regularização fundiária e urbanística de favelas pouco desenvolvida. O desenvolvimento desta etapa tem como foco a base de periódicos Scopus, que abarca 16.500 revistas peer-reviewed, e os artigos publicados no Simpósio Brasileiro de Sensoriamento Remoto (SBSR). Estas fontes de publicações foram escolhidas pela acessibilidade, protagonismo e pelo grande volume de conteúdo relevante para este tipo de pesquisa. O recorte temporal adotado para o SBSR compreende os três últimos eventos (2013, 2015 e 2017), uma vez que os mesmos ofereceram uma sessão temática exclusiva para o tema.

\section{RESULTADOS}

\section{OS VANTS E A FAVELA: O QUE É POSSÍVEL?}

Os VANTs ultrapassam os muros da pesquisa acadêmica e tendem a entrelaçar universidade, comunidade e sociedade. Países com altos índices de desigualdade e pobreza tendem a se beneficiar de forma mais efetiva dessa tecnologia, uma vez que apresentam desafios urbanos maiores.

Não é coincidência que em países como o Brasil as favelas sejam um buraco nos mapas oficiais e essa falta de informações reflete, em boa parte dos casos, um posicionamento e uma escolha política e ideológica: nessa visão, não se deve oficializar, através da coleta de dados, algo que não deveria existir. Então, desde o início, o mapeamento de favelas com uso de VANTs tem um impacto ideológico evidente e, também, tem o poder de construção indenitária para as comunidades que pode converter-se em empoderamento.

Podem-se distinguir três níveis de dados necessários aos projetos de melhorias em favelas e correlacionar tais dados às possibilidades de aquisição de forme direta, indireta ou não passíveis de aquisição por meio de imageamento com drones (Gevaert et al., 2018) (tabela 1):

Tabela 1: Exemplos de informações derivadas de mapeamento por VANT. Fonte: Adaptado de Gevaert et. al., 2018.

\begin{tabular}{ccc}
\hline $\begin{array}{c}\text { Aquisição direta por imagens } \\
\text { obtidlas através de VANTs }\end{array}$ & $\begin{array}{c}\text { Necessita de } \\
\text { outras fontes }\end{array}$ \\
\hline Vias & Uso do solo & $\begin{array}{c}\text { Contagens } \\
\text { populacionais e } \\
\text { outras informações } \\
\text { censitárias }\end{array}$ \\
Limites de & Locais de despejo & Renda, etc. \\
edificações & de lixo & Limites \\
Vegetação & Infraestrutura \\
urbana & administrativos \\
Modelos de & Informações \\
elevação & contextuais & \\
Modelos de & Atributos das \\
terreno & feições, tais como: \\
& tipo de telhado, \\
& número de \\
& pavimentos, \\
& material \\
& construtivo, etc & \\
\hline
\end{tabular}

Tais características de dados gerados por VANTs têm ampliado seu uso para o mapeamento de favelas em todo o mundo. Exemplos vêm, em geral, de países em desenvolvimento e subdesenvolvidos, onde o padrão de informalidade de ocupação da terra é maior, demandando um maior desenvolvimento desta tecnologia para regularização fundiária, cadastro, controle de áreas de risco, saneamento, etc.

A Slum Rehabilitation Authority (Autoridade de Reabilitação de Favelas), responsável pelo controle e gestão de favelas na Índia, iniciou um projeto para mapear todas as moradias localizadas em favelas na cidade de Mumbai com VANTs para reabilitação urbana e regularização fundiária (THE TIMES OF INDIA, 2018). 
Outros exemplos mostram a colaboração entre governos locais, terceiro setor e universidades, como nos casos dos mapeamentos com VANTs realizados pela universidade de Twenty/ITC, da Holanda, nas favelas de Kigali em Ruanda (África), além de iniciativas em Maldonado (Uruguai) e Tandale na Tanzânia (África).

Gevaert et al. (2017) investigaram como os aspectos radiométricos e texturais $2 \mathrm{D}$, características topográficas 2.5D e características geométricas 3D obtidas a partir de aerolevantamentos embarcados em VANTs podem ser integrados para obter uma classificação automatizada de elevada precisão para favelas. Para tanto, trabalharam com conjuntos de dados de assentamentos em Kigali (Ruanda) e Maldonado (Uruguai). As descobertas demonstraram que a integração de características $2 \mathrm{D}$ e 3D levaram a uma precisão geral de $91,6 \%$ e 95,2\% respectivamente para a identificação de feições em assentamentos informais.

Koeva et al. (2016) procuraram demonstrar o potencial de uso de VANTs para criação e atualização de mapas a partir do emprego de VANT em uma favela localizada na cidade de Kigali (Ruanda). Foram recolhidas 954 imagens com um quadricóptero DJI Phantom 2 Vision Plus. Como resultado, foi produzida uma ortofoto cobrindo $0,095 \mathrm{~km}^{2}$ com uma resolução espacial de $3,3 \mathrm{~cm}$. Essa ortofoto foi utilizada para extrair feições com precisão subdecimétrica, incluindo uma atualização cadastral. Foram realizados controles quantitativo e qualitativo dos produtos que indicaram que as precisões obtidas estão de acordo com padrões internacionais. A coleta de pontos de controle de alta precisão em campo permitiu gerar dados planimétricos com precisões verticais inferiores a 8 $\mathrm{cm}$, cumprindo assim os requisitos para mapas na escala 1: 1000.

Gevaert et al. (2015), também a partir da pesquisa realizada na cidade de Kigali (Ruanda), avaliam que os benefícios do aerolevantamento com VANTs permitem fornecer informações mais precisas e adicionais, anteriormente inacessíveis, reduzindo o trabalho de campo e fornecendo uma base para a comunicação entre as partes interessadas.

Birriel et al. (2016) realizaram em Maldonado, no Uruguai, uma pesquisa sobre um assentamento irregular de alta densidade. A pesquisa procurou cartografar os elementos existentes, incluindo casas, cercas, passagens, ruas e escoamento superficial. Foi usado o quadricóptero md41000 da Microdone. Foi usada uma câmera SONY Nex7 de 24MP com uma lente com distância focal de $16 \mathrm{~mm}$. A altitude de voo foi fixada em $80 \mathrm{~m}$ acima do solo e a programação de voos foi realizada usando o software mdCockpit. Foi definida a sobreposição longitudinal de $66 \%$ e latera de 25\%. Também foram estabelecidos pontos de apoio antes da execução dos voos. Cruzes brancas foram pintadas com spray (marcadores). Esses pontos foram extraídos com Gps Rtk de dupla frequência. Foram atingidas precisões planimétricas entre 1.7 e 2.5 $\mathrm{cm}$ e altimétricas entre 5 e 5.6 centímetros.

Em Tandale, uma das maiores favelas de Dar es Salaam, na Tanzânia, as autoridades municipais estão usando VANTs para elaborar planos para proteger e ajudar as comunidades em risco de inundação. Apelidado de
Ramani Huria (Mapeamento Aberto), o projeto procura criar mapas precisos que podem ser usados para reduzir os riscos de enchentes e melhorar a resposta a desastres. O mapeamento com VANTs permitiu criar modelos de risco de inundação e um plano de resiliência comunitária (preparação e resposta a desastres), com a definição das rotas de evacuação. Essa iniciativa também treinou estudantes universitários e membros da comunidade para identificar e mapear as áreas mais propensas a serem atingidas pelas enchentes, permitindo que as autoridades locais atuem em tempo real. Os mapas produzidos são fáceis de usar podem ser usados por pessoas com qualquer nível de educação (Makoye, 2017).

A exemplo destas práticas no Brasil, cumpre mencionar o trabalho de Langoni et al. (2018), que empregaram um VANT na favela do Banhado, localizada no município de São José dos Campos - SP. Para a realização do aerolevantamento foram utilizados um VANT DJI Phantom 4 Pro (equipado com uma câmera com sensor CMOS de 20 MP e lente com abertura f/2.8) e o aplicativo PIX4D Capture, para delimitação do plano de voo. Para gerar o modelo tridimensional (3D), a ortofoto e as curvas de nível com equidistância de $1 \mathrm{~m}$, foi utilizado o Software Agisoft PhotoScan 1.2.4. Foi coberta uma área de $144.968 \mathrm{~m}^{2}$ a partir de 251 imagens adquiridas. O voo foi conduzido a uma altura média de 100 metros e com uma sobreposição de fotos lateral e longitudinal de $80 \%$. Após a fase de aquisição das imagens, seguiu-se a fase de processamento destes dados com transformações aplicadas sobre as imagens baseadas no método SIFT (Scale Invariant Feature Transform). Como resultado, em conjunto com levantamentos realizados em campo, foi possível, através de fotointerpretação, obter a totalidade dos gabaritos das residências da área de levantamento e realizar a vetorização dos limites dos lotes, inclusive daqueles onde a equipe de campo não obteve acesso em face da ausência de moradores ou da presença de barreiras visuais. Também foi possível delimitar as valas e valetas de esgoto, assim como as regiões com concentração de resíduos sólidos (figura 1).

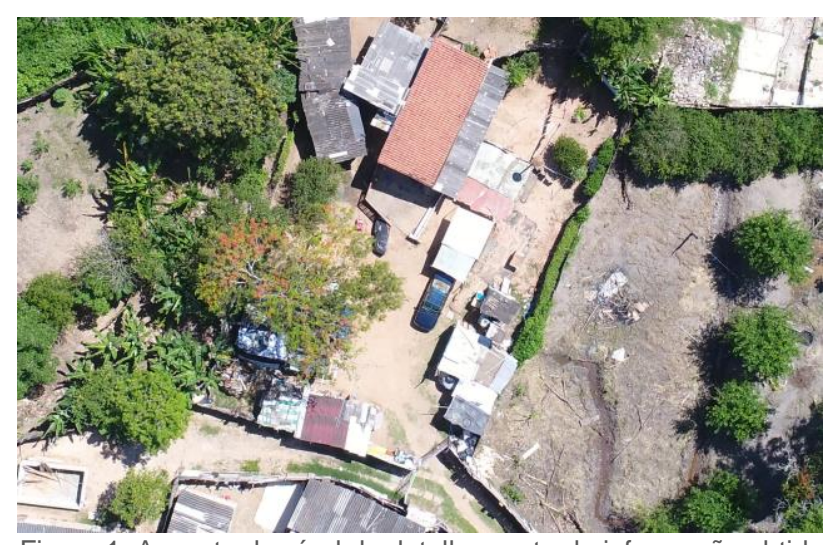

Figura 1: Aspecto do nível de detalhamento de informação obtida com o aerolevantamento na favela do Banhado (São José dos Campos - SP). Fonte: Langoni et al., 2018. 


\section{ASPECTOS ÉTICOS E NORMATIVOS}

Os VANTs estão sujeitos às normas, registros e autorizações da Agência Nacional de Aviação Civil (ANAC), responsável por regular e fiscalizar as atividades relacionadas à aviação civil, incluindo a certificação de equipamentos; do Departamento de Controle do Espaço Aéreo (DECEA), responsável por realizar o controle do espaço aéreo brasileiro e da Agência Nacional de Telecomunicações (ANATEL), responsável pela homologação dos transmissores de rádio frequência (tabela 2).

Tabela 2: Normas relacionadas ao registro e à operação de VANTs. Fonte: Ministério da Defesa, 2018.

\begin{tabular}{|c|c|}
\hline $\begin{array}{l}\text { RBAC E no 94, de } 02 \text { de } \\
\text { maio de } 2017\end{array}$ & $\begin{array}{l}\text { Requisitos gerais para aeronaves não } \\
\text { tripuladas de uso civil; }\end{array}$ \\
\hline $\begin{array}{l}\text { Resolução ANAC no } 419 \text {, } \\
\text { de } 02 \text { de maio de } 2017\end{array}$ & $\begin{array}{l}\text { Aprova o Regulamento Brasileiro de } \\
\text { Aviação Civil Especial n 94; }\end{array}$ \\
\hline $\begin{array}{l}\text { ICA } 100-40 \text {, de } 22 \text { de } \\
\text { dezembro de } 2016\end{array}$ & $\begin{array}{c}\text { Sistemas de Aeronaves Remotamente } \\
\text { Pilotadas e o Acesso ao Espaço Aéreo } \\
\text { Brasileiro; }\end{array}$ \\
\hline $\begin{array}{l}\text { Resolução ANAC no } 377 \text {, } \\
\text { de } 15 \text { de março de } 2016\end{array}$ & $\begin{array}{l}\text { Regulamenta a outorga de serviços } \\
\text { aéreos públicos para empresas } \\
\text { brasileiras e dá outras providências; }\end{array}$ \\
\hline $\begin{array}{l}\text { Portaria Normativa no } \\
\text { 953/MD, } 16 \text { de abril de } \\
2014\end{array}$ & $\begin{array}{c}\text { Dispõe sobre a adoção de procedimentos } \\
\text { para a atividade de aerolevantamento no } \\
\text { Território Nacional; }\end{array}$ \\
\hline $\begin{array}{l}\text { ICA } 63-13 \text {, de } 11 \text { de } \\
\text { novembro de } 2013\end{array}$ & $\begin{array}{l}\text { Procedimentos dos Órgãos do SISCEAB } \\
\text { Relacionados com AVOEM, AVANAC e } \\
\text { AVOMD; }\end{array}$ \\
\hline $\begin{array}{c}\text { Decreto } \mathrm{n}^{\circ} 7.845 \text {, de } 14 \\
\text { de novembro de } 2012\end{array}$ & $\begin{array}{l}\text { Regulamenta procedimentos para } \\
\text { credenciamento de segurança e } \\
\text { tratamento de informação classificada } \\
\text { em qualquer grau de sigilo, e dispõe } \\
\text { sobre o Núcleo de Segurança e } \\
\text { Credenciamento; }\end{array}$ \\
\hline $\begin{array}{l}\text { Lei ํํ } 11.182 \text {, de } 27 \text { de } \\
\text { setembro de } 2005\end{array}$ & $\begin{array}{l}\text { Cria a Agência Nacional de Aviação Civil, } \\
\text { ANAC, e dá outras providências; }\end{array}$ \\
\hline $\begin{array}{l}\text { Decreto № } 2.278 \text {, de } 17 \\
\text { de julho de } 1997\end{array}$ & $\begin{array}{l}\text { Regulamenta as Atividades de } \\
\text { Aerolevantamento no Território Nacional; }\end{array}$ \\
\hline $\begin{array}{l}\text { Lei oㅜ } 7.565 \text {, de } 19 \text { de } \\
\text { dezembro de } 1986\end{array}$ & igo Brasileiro de Aeronáutica; \\
\hline $\begin{array}{l}\text { Decreto-Lei no } 1.177 \text {, de } \\
21 \text { de junho de } 1971\end{array}$ & $\begin{array}{l}\text { Dispõe sobre aerolevantamentos no } \\
\text { território nacional, e dá outras } \\
\text { providências. }\end{array}$ \\
\hline $\begin{array}{l}\text { Decreto-Lei no } 89.817 \text {, de } \\
20 \text { de junho de } 1984\end{array}$ & $\begin{array}{l}\text { Instruções Reguladoras das Normas } \\
\text { Técnicas da Cartografia Nacional }\end{array}$ \\
\hline
\end{tabular}

Em síntese, a partir do Regulamento Brasileiro de Aviação Civil Especial 94/2017 (RBAC-E) da ANAC, os VANTs são divididos em duas categorias: aeromodelo (recreação) e Aeronave Remotamente Pilotada (Remotely-Piloted Aircraft - RPA) (voos experimentais, comerciais ou institucionais). A operação de RPA é restrita a áreas com no mínimo 30 metros horizontais de distância de terceiros não anuentes. Somente aeromodelos com peso máximo de decolagem (equipamento, bateria e carga) de até 250 gramas não precisam ser cadastrados junto à ANAC. Em geral, os aeromodelos utilizados para aerolevantamento em favelas possuem peso máximo de decolagem superior a $250 \mathrm{~g}$ até $25 \mathrm{~kg}$ (classe 3) e são operados em linha de visada visual até 400 pés (cerca de 120 metros) acima do nível do solo. Portanto, eles devem ser cadastrados na ANAC e, nesses casos, o piloto remoto deve possuir maioridade civil, licença para o voo e habilitação. Além disso, ele deve portar uma série de documentos, incluindo: Certidão de Cadastro; Certificado de Matrícula; manual de voo; apólice de seguro com comprovante de pagamento e comprovante da avaliação de risco (Brasil, 2017a).
O uso do espaço aéreo por RPA (VANT) é regulamentado pela ICA (Instrução do Comando da Aeronáutica) 100-40 do DECEA (Brasil, 2017b), assim como pelo Código Brasileiro de Aeronáutica (CBA) (Brasil, 1986).

Para o acesso comercial ao espaço aéreo brasileiro, uma RPA é considerada uma aeronave como outra qualquer, devendo o piloto se cadastrar e solicitar autorização de voo no SARPAS (Solicitação de Autorização de Uso de RPAS) com antecedência para uma análise de tráfego aéreo. Os prazos para avaliação da solicitação dependem das características da operação pretendida e variam de 45 minutos a 18 dias em relação ao início das atividades.

É importante frisar que, sobretudo nas regiões metropolitanas, onde se concentram grande parte das favelas brasileiras, as zonas restritas para operação de RPA abrangem grande parte das cidades. Como resultado, as análises de tráfego aéreo têm levado as solicitações de autorização de aerolevantamento para o processo mais longo dos três modelos de processos existentes no SARPAS, incidindo, também, pareceres negativos para essas solicitações. Existem também dúvidas e questionamentos a respeito dos critérios para a definição de certas zonas restritas para voo, principalmente quando estas não estão localizadas próximas a aeródromos e rotas de aeronaves (figura 2).

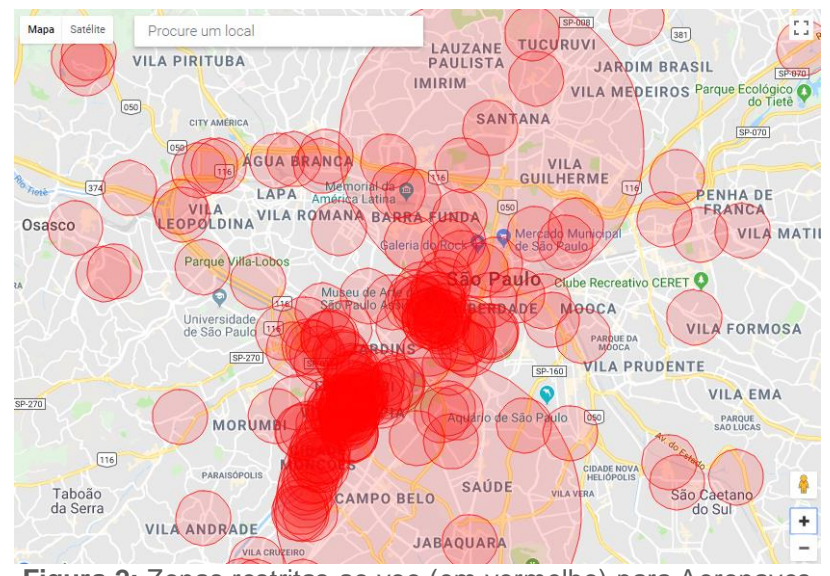

Figura 2: Zonas restritas ao voo (em vermelho) para Aeronaves Remotamente Pilotadas (RPA) na Região Metropolitana de São Paulo. Fonte: Ministério da Defesa, 2018.

Outro dilema enfrentado para a legalização dos aerolevantamentos de baixo custo em favelas é a legislação vigente que, por ser da década de 1970 (Decreto-Lei no 1.177/1971), não faz distinção entre o tipo de aeronave a ser utilizada para a execução dessa atividade e, também, não estabelece nenhuma flexibilidade para operações com objetivos especiais de interesse social, como no caso da regularização fundiária urbana. Essencialmente, tal legislação advém de uma época onde os VANTs eram rudimentares e experimentais e o controle rígido dos aerolevantamentos era necessário em face de questões estratégicas de segurança e soberania nacional que foram superadas pela popularização das imagens de satélite de alta resolução. 
Atualmente, o Decreto-Lei 1.177/1971 limita a execução de aerolevantamentos no território nacional a organizações especializadas do Governo Federal, governos estaduais e organizações privadas (pessoas jurídicas) credenciadas no Ministério da Defesa (MD).

Portanto, uma empresa não cadastrada no MD não pode participar de licitações públicas ou celebrar contrato com particulares para a execução de atividades de aerolevantamento.

A ANEA (Associação Nacional de Empresas de Aerolevantamento), que congrega os grandes players do setor, advoga que aerolevantamento com VANTs que possuem objetivos cartográficos são ilegais em face da ausência de regulamentação. Além disso, consideram que os produtos derivados de aerolevantamento executado por VANTs, sem as devidas licenças, podem ser questionados judicialmente (ANEA, 2018).

Cumpre mencionar que, além de sanções de natureza administrativa, cível e penal, incidem sobre as empresas que atuarem de forma irregular as penalidades previstas nos artigos 24 a 26 do Decreto Federal 2.278/1997 (Brasil, 1997).

Pode-se afirmar que os procedimentos de cadastramento, burocráticos e custosos, restringem sobremaneira 0 número de empresas aptas a prestar esse tipo de serviço. Uma regulação mais flexível para o setor pode ser identificada como uma questão primordial para democratizar o acesso à informação espacial, uma vez que as incertezas jurídicas e o alto custo dos serviços de aerolevantamento cobrados por grandes empresas impedem ou no mínimo dificultam o acesso de pequenas prefeituras, assessorias técnicas em habitação de interesse social e comunidades de baixa renda a esses serviços, além de inibir a emergência de empresas especializadas em aerolevantamento de baixo custo.

Além disso, é importante que o Ministério das Cidades estabeleça critérios para aplicação e avaliação de produtos gerados a partir de aerolevantamentos com VANTs para a regularização fundiária de núcleos urbanos informais ocupados por população de baixa renda (Reurb - S) em sintonia com a Lei Federal 13.465/2017 (Lei de Regularização Fundiária) (Brasil, 2017c). O Incra (Instituto Nacional de Colonização e Reforma Agrária), por exemplo, anunciou normas para o uso de VANTs no georreferenciamento de propriedades rurais através da Norma de Execução Incra/DF/02. Essa norma definiu os padrões de precisão de acordo com os tipos de limites das propriedades e a necessidade de se atender as demais exigências do Manual Técnico de Posicionamento do Incra.

Outra questão importante a se observar são as sanções cíveis, penais e administrativas que envolvem a operação irregular de um VANT. O Código Brasileiro de Aeronáutica - CBA (Lei no 7.565/1986) traz as sanções administrativas no seu artigo 289, incluindo multa, para pilotos de aeronaves que infringem quaisquer orientações citadas neste regulamento e nos demais regulamentos de acesso ao espaço aéreo. Além disso, os operadores de VANTs estão sujeitos a sanções penais e cíveis quando expuserem a vida ou a saúde de alguém em perigo e, também, quando colocarem em perigo embarcação ou aeronave (artigos 132 e 261 do Código Penal). Já a Lei das Contravenções Penais (art. 33) define as sanções para quem dirigir aeronave sem estar devidamente licenciado e, no art. 35, as infrações para quem realizar acrobacias ou voos rasantes fora da zona legalmente permitida, ou fazer descer a aeronave fora dos lugares destinados a esse fim.

No caso das sanções cíveis, o Código Civil define que aquele que, por ação ou omissão voluntária, negligência ou imprudência, violar direito e causar dano a outrem, ainda que exclusivamente moral, comete ato ilícito (art. 186) (Brasil, 2002).

Especificamente no que se refere à privacidade, cumpre destacar que em seu artigo $5^{\circ}$, inciso X, a Constituição Federal estabelece como "invioláveis a intimidade, a vida privada, a honra e a imagem das pessoas, assegurado o direito a indenização pelo dano material ou moral decorrente de sua violação" (Brasil, 1988).

Como o grande potencial dos VANTs para o fornecimento de informações geoespaciais contrasta com os riscos de exposição da vida privada, da honra e da imagem das pessoas, principalmente em face do uso indevido dos dados coletados, considerações acerca do uso ético desses equipamentos são fundamentais.

Assim, em que pese à falta de normas atinentes ao uso de VANTs e questões de privacidade no Brasil, a operação desses equipamentos em assentamentos precários (favelas) demandam cuidados que envolvem a participação e o controle social da atividade, assim como a ampla notificação dos moradores sobre as atividades a serem desenvolvidas. Para tanto, as associações de moradores cumprem um papel fundamental. É a partir delas que se faz a aprovação do aerolevantamento (licença social) e que se assegura a ampla divulgação do período em que a operação será realizada e do tipo de informação que será fotografada. O apoio a essa ampla divulgação pode também se dar pela colagem de cartazes, distribuição de informativos e redes sociais.

Gevaert et. al. (2018) ponderam que o sobrevoo com VANT permite identificar pessoas dentro de um espaço privado, ensejando a necessidade de informar os cidadãos sobre os direitos de acesso, processamento e distribuição das fotografias, assim como sobre as formas de mitigar as preocupações de privacidade, definindo assim diretrizes para o nível de abstração e distribuição da informação coletada. Nesse sentido, em primeiro lugar, esse tipo de aerolevantamento deve estar lastreado pela participação social, responsabilidade, transparência, empoderamento e equidade, valores balizadores das políticas e projetos de urbanização. Isso dá aos moradores o poder de mover ou cobrir objetos móveis para que os mesmos não sejam fotografados e, também, ajuda a definir os objetos não removíveis que serão borrados antes da distribuição ao público. Em segundo lugar, vale lembrar que o conceito de informação sensível ou privacidade pode variar entre pessoas, grupos e culturas. Sendo assim, a consideração dos objetos e espaços privados pelas comunidades locais pode ser bem diferente e isso deve ser tomado em consideração. 
CAMINHOS DA PRODUÇ̃̃O CIENTÍFICA: DESAFIOS PARA O ESTÍMULO DA PESQUISA COM VANTS EM FAVELAS

O relatório produzido pela consultoria Pricewaterhouse Coopers \& Associados (PwC) constatou que os VANTs, principalmente a partir das evoluções recentes na velocidade de voo, no aumento na capacidade de carga útil e nas soluções de coleta de dados em tempo real, envolvem um mercado global emergente de 112 bilhões de euros, sendo 39,7 bi para o setor de infraestrutura (inspeção, aerofotogrametria, acompanhamento de obras, transporte de materiais e equipamentos); 28,5 bi para o setor agrícola (coleta e análise de dados sobre propriedades, culturas e pulverização de precisão); 11,4 bi para o setor de transportes; 8,8 bi para a indústria da segurança e 7,7 bi para indústria de mídia e entretenimento (PwC, 2017).

A busca ativa por palavras-chave realizada na base de periódicos Scopus indica um crescimento exponencial das pesquisas associadas aos VANTs nos últimos cinco anos e uma forte correlação entre a produção científica global e os nichos de mercado apresentados no relatório da PwC. Além disso, é notória a forte concentração de pesquisas que envolvem a aplicação de VANTs no campo do monitoramento e da conservação ambiental (tabela 3).

Tabela 3: Publicações envolvendo uso de drones em áreas de aplicação selecionadas. Fonte: Scopus. Organizado pelos autores.
Tabela 4: Publicações envolvendo uso de drones em áreas de aplicação selecionadas. Fonte: Simpósio Brasileiro de Sensoriamento Remoto. Organizado pelos autores.

\begin{tabular}{ccccc}
\hline SETOR & 2013 & 2015 & 2017 & TOTAL \\
$\begin{array}{c}\text { Conservação e } \\
\text { monitoramento } \\
\text { ambiental }\end{array}$ & 2 & 6 & 10 & 18 \\
$\begin{array}{c}\text { Agricultura e } \\
\text { silvicultura }\end{array}$ & 1 & 7 & 5 & 13 \\
$\begin{array}{c}\text { Topografia e } \\
\text { cartografia } \\
\text { digital }\end{array}$ & 1 & 7 & 5 & 13 \\
$\begin{array}{c}\text { Construção } \\
\text { civil }\end{array}$ & 0 & 1 & 0 & 1 \\
$\begin{array}{c}\text { Mineração } \\
\text { Cadastro }\end{array}$ & 1 & 0 & 1 & 2 \\
\hline $\begin{array}{c}\text { multifinalitário } \\
\text { Assentamentos } \\
\text { precários } \\
\text { (favelas) }\end{array}$ & 0 & 0 & 0 & 1 \\
\hline
\end{tabular}

A baixa produção científica associada à utilização de VANTs em assentamentos precários (favelas) frente às potencialidades e desafios do empego dessa ferramenta em levantamentos planialtimétricos e cadastrais de baixo custo evidencia a necessidade de se estabelecer uma estratégia de formação e qualificação do corpo docente e discente das universidades com este olhar. Para tanto, é preciso construir e fortalecer uma rede colaborativa de ensino, pesquisa e extensão nos cursos de arquitetura e urbanismo e áreas afins que se encarregue de viabilizar as articulações político-científicas necessárias ao avanço dessa temática.

No campo do ensino, por exemplo, as pesquisas desenvolvidas poderiam ser apropriadas pelas aulas de topografia, sensoriamento remoto e geoprocessamento e, ao mesmo tempo, difundidas através de programas de extensão.

Os programas de extensão universitária são de fundamental importância para que essa estratégia seja fortalecida, pois eles permitem ativar uma via de mão dupla envolvendo universidades, movimentos sociais assessorias técnicas e comunidades que lutam pela regularização fundiária de seus bairros. Isso permitirá, por um lado, garantir a apropriação dessas inovações e soluções desenvolvidas no campo acadêmico pela sociedade e, por outro, estabelecer um diálogo de docentes e discentes com as lutas e resistências por moradia.

Considera-se assim contribuir para os desafios das universidades brasileiras delimitados por Fiuza et al. (2009), compreendendo a busca por um padrão de qualidade compatível com o estado de evolução e dinamização do conhecimento científico no mundo contemporâneo e, também, o desenvolvimento de programas sociais que utilizem as geotecnologias para superação de problemas nacionais inadiáveis, com foco na exclusão e carência socialmente estrutural, incluindose aí o tema da moradia. 
Assim, associar a pesquisa e o ensino com VANTs, principalmente no campo da arquitetura e do urbanismo, aos vínculos orgânicos entre a universidade e a sociedade civil, conforme definido por Fiuza et. al (2009, p. 300-301), permitirá compromissar os projetos científicos e pedagógicos com a realidade socioeconômica nacional de forma a esclarecer que "a sociedade inclui o setor empresarial e seus valores, mas também as classes trabalhadoras, as organizações e os movimentos sociais, bem assim seus valores".

Essa perspectiva permitirá construir uma apropriação tecnológica que não seja meramente instrumental das geotecnologias em geral e do sensoriamento remoto embarcado em VANTs em específico, formando discentes e pesquisadores sensíveis, responsáveis e conscientes dos problemas sociais do país.

\section{DISCUSSÃO}

Geralmente as áreas de assentamentos irregulares são caracterizadas por um grande adensamento habitacional com construções precárias. Do ponto de vista urbano ambiental essas áreas podem apresentar problemas como alagamentos e falta de segurança pela ocupação de áreas sujeitas a deslizamentos. Além disso, as vias podem apresentar um traçado irregular e com dimensões que dificultam o acesso à circulação de veículos.

Para o desenvolvimento de projetos que busquem a adequação legal e urbana desses assentamentos, levantamentos planialtimétricos e cadastrais são fundamentais e precedem os processos de projeto.

Com uma boa base de dados coletados, podem-se obter melhores resultados para o projeto, com soluções mais adequadas e economicamente viáveis. Do ponto de vista legal (Lei Federal 13.465/2017), para a regularização fundiária é necessário o levantamento preciso das áreas ocupadas pelas construções, delimitação das divisões dos lotes, materialidade e topografia do local ocupado. Para o desenvolvimento de projetos urbanísticos que visem à adequação do acesso aos serviços de drenagem e esgoto é necessário um levantamento dos traçados e dimensões das vias, e da topografia para a caracterização de áreas de alagamentos e de conflitos ambientais. (Brasil, 2017)

Com base nas características dos assentamentos precários e na necessidade de uma caracterização precisa desses territórios, percebe-se uma imensa dificuldade em resolver essas questões a partir de um levantamento planialtimétrico e cadastral "tradicional" (Birriel et al., 2016). A dificuldade de acesso a alguns lugares, incluindo áreas alagáveis e o interior das divisões dos lotes, assim como a dificuldade de caracterização de diversos aspectos a partir do levantamento em campo, faz com que o levantamento aerofotogramétrico embarcado em VANTs seja a melhor opção.

O trabalho de assessorias técnicas junto aos movimentos de moradia também pode apresentar avanços técnicos e políticos com a utilização de tecnologias que permitam um melhor entendimento do território e nos processos participativos com as comunidades.
Nesse sentido, vale lembrar que as ideias de participação e descentralização estruturaram as pautas políticas dos movimentos sociais no decorrer da década de 1980, pósfim da ditadura militar. Iniciavam-se, também neste período, articulações entre arquitetos, engenheiros, psicólogos, assistentes sociais e os movimentos que lutavam por condições dignas de moradia em torno da pauta da autogestão. Isso parte do que se acreditava ser a melhor modalidade para que se formassem novos agentes sociais, colocando como protagonistas políticos aqueles que geralmente eram objeto das políticas habitacionais. Isso deu início ao que se convencionou chamar de assessorias técnicas. (Barros, 2013)

Partindo desse pressuposto, do trabalho das assessorias técnicas, a utilização de tecnologias para levantamentos a baixo custo, também se caracteriza como um avanço político nos processos de participação daquele morador ou usuário. Com esse tipo de levantamento pode-se obter dados precisos para levantamentos que sirvam de base para o desenvolvimento das discussões em relação às estratégias políticas de permanência em um local com risco de remoção ou para discussões de projeto e acompanhamento de uma obra autogerida. Com o decorrer do desenvolvimento do processo de projeto, podemos destacar que esta ferramenta pode auxiliar nas discussões a respeito de ações que necessitam da participação do morador como, por exemplo, realocações de moradias que se encontram em risco e traçados das vias que permitam a estruturação de uma rede de serviços urbanos como luz, água e esgoto.

De modo autônomo os arquitetos e os moradores começam a se articular em torno de ferramentas mais avançadas inserindo novas condições de trabalho e de autonomia.

O desenvolvimento de pesquisas científicas nas universidades relacionadas às tecnologias que possam contribuir neste processo é fundamental para que se avance em ações que dão maior autonomia e solidez para as assessorias e os movimentos sociais e, consequentemente, em ações políticas que visem à modificação da realidade.

Se a ideia de alterar a estrutura do desenho e da produção arquitetônica determina 0 trabalho das assessorias, a utilização de tecnologias para levantamentos mais acessíveis aproxima o trabalhador de mais uma etapa da constituição do projeto e corrobora para a inversão do papel da tecnologia na sociedade.

Além disso, os trabalhos que envolvem a luta contra um processo de remoção de moradores de uma favela implicam em contrapor os argumentos apresentados pelo poder público. Muitas vezes, são apresentadas justificativas ambientais ou de risco para remover comunidades que, na verdade, são vítimas da especulação imobiliária. Com as informações territoriais produzidas pelos VANTs é possível auxiliar profissionais e comunidades na contraposição dos fatores técnicos apresentados para remoções de moradias com argumentos técnicos mais precisos, discutindo a importância da permanência de uma determinada comunidade no local alvo de despejos forçados. 
Em geral, os levantamentos que se têm acesso sobre favelas são desatualizados, pouco precisos e definem poucas características sobre a área ocupada. Nessas situações, o acesso a informações sobre esses territórios é dificultado por preferências sociais e econômicas, já que as prefeituras priorizam a atualização das suas bases cartográficas em regiões de maior interesse para o investimento imobiliário.

Diante desse fato, uma reversão, tanto do modo de se produzir a habitação quanto de se produzir informações espaciais sobre o local de moradia da classe trabalhadora, assim como do acesso a essa tecnologia pelos trabalhadores, significa um passo importante para a emancipação da consciência política.

Como já dito anteriormente, o trabalho relacionado à moradia em comunidades que lutam por esse direito não é, e nem deve ser, exclusividade dos arquitetos e de outros profissionais de nível universitário e, portanto, uma série de outras ações deve coincidir com os processos de trabalho das assessorias técnicas para que os moradores se apoderem das questões que os oprimem na sociedade.

Assim, conclui-se que para o desenvolvimento de trabalhos para a regularização fundiária e urbanística de favelas, tanto na perspectiva do gestor público, quanto na perspectiva das assessorias técnicas e movimentos de moradia organizados, a opção pelo aerolevantamento com VANT pode caracterizar um avanço técnico e político para a elaboração de projetos.
Brasil. (1988). Constituição da República Federativa do Brasil. Retrieved from http://www.planalto.gov.br/ccivil_03/constituic ao/constituicao.htm

Brasil. (1997). Decreto Federal 2.278. Retrieved from http://www.planalto.gov.br/ccivil_03/decreto/d2278.htm
Brasil. (2002). Código Civil. Lei Federal 10.406. Retrieved from http://www.planalto.gov.br/ccivil_03/Leis/2002//10406.htm

Brasil. (2017a). ANAC. Requisitos Gerais para Aeronaves Não Tripuladas de Uso Civil - RBAC-E no 94. Retrieved from http://www.anac.gov.br/assuntos/legislacao/legislacao-1/rbha -e-rbac/rbac/rbac-e-94-emd-00/@@display file/arquivo_norm a/RBACE94EMD00.pdf

Brasil. (2017b). DECEA. Sistemas de Aeronaves Remotamente Pilotadas e o Acesso ao Espaço Aéreo Brasileiro - ICA 100/40. Retrieved from https://publicacoes.decea.gov.br/?i= publicacao $\& i d=4510$

Brasil. (2017c). Lei Federal 13.465. Lei de Regularização Fundiária. Retrieved from http://www.planalto.gov.br/ccivil _03/_ato2015-2018/2017/lei/l13465.htm

Coelho, I. L. F., Fantin, M.; Pedrassoli, J. C. (2018). O uso de veículo aéreo não tripulado para a regularização fundiária e planejamento urbanístico de comunidades. ENEC, Rio de Janeiro, no prelo.

Gevaert, C., Sliuzas R., Persello, C., Vosselman, G. (2015). Opportunities for UAV mapping to support unplanned settlement upgrading. GeoTech Rwanda, 11 (18-20), 1-5. Retrieved from https://www.geotechrwanda2015.com/wpcontent/uploads/20 15/12/41a_Caroline-Gevaert.pdf

Gevaert, C., Persello, C., Sliuzas, R., Vosselman, G. (2017). Informal settlement classification using point-cloud and image-based features from UAV data, ISPRS Journal of Photogrammetry and Remote Sensing, 125, 225-236. Retrieved from https://www.sciencedirect.com/science/article/ pii/S0924271616301411

Gevaert, C.M., Sliuzas, R., Persello, C., Vosselman, G. (2018). Evaluating the Societal Impact of Using Drones to Support Urban Upgrading Projects. ISPRS Int. J. Geo-Inf, 7(91), 1-15. Retrieved from http://www.mdpi.com/2220-9964/7/3/91

IBGE (Instituto Brasileiro de Geografia e Estatística). Censo Demográfico. (1991). Disponível em https://biblioteca.ibge .gov.br/biblioteca-catalogo?id=782\&view=detalhes

IBGE (Instituto Brasileiro de Geografia e Estatística). Censo Demográfico. (2010). Disponível em https://ww2.ibge.gov.br/ home/estatistica/populacao/censo2010/default.shtm

Koeva, M., Muneza, M., Gevaert, C., Gerke, M., Nex, F. (2016). Using UAVs for map creation and updating. A case study in Rwanda, Survey Review, 50 (361), 1-14. Retrieved from https://www.tandfonline.com/doi/full/10.1080/00396265.2016. 1268756

Makoye, K. (2017, jan 04). Drones help communities map flood risk in Dar es Salaam slums. Reuters. Retrieved from https://www.reuters.com/article/us-tanzania-disaster-floodsdrones/drones-help-communities-map-flood-risk-in-dar-essalaam-slums-idUSKBN14O0M8

PWC (Pricewaterhouse Coopers) Mercado global de aplicações comerciais baseadas em drones valem $€ 112$ mil milhões. (2017). Retrieved from https://www.pwc.pt/pt/sala-imprensa/ press-room/2017/mercado-global-aplicacoes-drones.html

The Times of India In a first, Slum Rehabilitation Authority to use drone tech to map slums. (2018). Retrieved from https://timesofindia.indiatimes.com/city/mumbai/in-a-first-srato-use-drone-tech-to-map-slums/articleshow/62575273.cms 